\title{
Minimal changes in the B- and T-cell compartments of school-aged children with haploinsufficiency of filaggrin: The Generation $R$ Study
}

\author{
Kirsten Looman ${ }^{1}$, Minke van Mierlo ${ }^{2}$, Menno van Zelm³ ${ }^{3}$ Chen $\mathrm{Hu}^{4}$, Liesbeth Duijts ${ }^{5}$, \\ Johan de Jongste ${ }^{2}$, Tamar Nijsten ${ }^{2}$, Luba Pardo ${ }^{6}$, Jessica Kiefte ${ }^{7}$, Henriëtte Moll ${ }^{5}$, and \\ Suzanne Pasmans ${ }^{2}$ \\ ${ }^{1}$ Erasmus University Medical Center \\ ${ }^{2}$ Erasmus MC \\ ${ }^{3}$ Central Clinical School, Monash University and Alfred Hospital \\ ${ }^{4}$ Erasmus Universiteit Rotterdam \\ ${ }^{5}$ Erasmus Medical Center \\ ${ }^{6}$ Erasmus MC University Medical Center Rotterdam \\ ${ }^{7} \mathrm{LUMC}$
}

December 10, 2020

\begin{abstract}
Background: Mutations in the filaggrin gene (FLG) affect epidermal barrier function and increase the risk of atopic dermatitis (AD). We hypothesized that FLG mutations affect immune cell composition in a general pediatric population. Therefore, we investigated if school-aged children with and without FLG mutations have differences in immune cell numbers. Methods: This study was embedded in a population-based prospective cohort study, the Generation R Study, and included 523 children of European genetic ancestry aged 10 years. The most common FLG mutations in the European population (R501X, S1085CfsX36, R2447X and S3247X) were genotyped. Additionally, 11-color flow cytometry was performed on peripheral blood samples to determine helper $\mathrm{T}(\mathrm{Th})$, regulatory $\mathrm{T}$ (Treg) and CD27+ and CD27- memory B cells. Sensitivity analysis was performed in $102 \mathrm{AD}$ cases, assessed by parental questionnaires. Results: FLG mutations were observed in $8.4 \%$ of the total population and in $15.7 \%$ of the AD cases. Children with any FLG mutation had higher Th22 cell numbers compared to FLG wild-type children. Children with and without FLG mutations had no difference in Th1, Th2, Th17, Treg or memory B cell numbers. Furthermore, in children with AD, FLG mutation carriership was not associated with differences in T- and B-cells or their subsets. Conclusions: School-aged children with FLG mutations have higher Th22 cell, which might suggest an immunological defense mechanism to an altered skin barrier function. No associations between Th or Treg cells and FLG mutations suggests that FLG mutations do not otherwise affect immune composition in a general pediatric population.
\end{abstract}

\section{TITLE PAGE}

Title

Minimal changes in the B- and T-cell compartments of school-aged children with haploinsufficiency of filaggrin: The Generation R Study

\section{Short Title}

Filaggrin haploinsufficiency and B and T cell subsets 
Word count: 2488

Number of figures: 3

Number of tables: 1

Electronic repository: 1 table, 2 figures

\section{Author names and affiliations}

Kirsten I.M. Looman ${ }^{1,2 *}$, Minke M.F. van Mierlo ${ }^{3 *}$, Menno C. van Zelm ${ }^{4}$, Chen $\mathrm{Hu}^{1,3}$, Liesbeth Duijts ${ }^{5,6}$, Johan C. de Jongste ${ }^{1,5}$, Tamar Nijsten ${ }^{3}$, Luba M. Pardo ${ }^{3}$, Jessica C. Kiefte-de Jong ${ }^{7}$, Henriëtte A. Moll ${ }^{2}$, Suzanne G.M.A. Pasmans ${ }^{3}$

* Authors denote equal contribution.

1 The Generation R Study Group, Erasmus MC, University Medical Center Rotterdam, Rotterdam, the Netherlands. ${ }^{2}$ Department of General Pediatrics, Erasmus MC, University Medical Center Rotterdam- Sophia Children's Hospital, Rotterdam, the Netherlands. ${ }^{3}$ Department of Dermatology, Erasmus MC, University Medical Center Rotterdam-Sophia Children's Hospital-Center of Pediatric Dermatology, Rotterdam, the Netherlands. ${ }^{4}$ Department Immunology and Pathology, Central Clinical School, Monash University and The Alfred Hospital, Melbourne, VIC, Australia. ${ }^{5}$ Department of Pediatrics, Division of Respiratory Medicine and Allergology, Erasmus MC, University Medical Center Rotterdam, Rotterdam, the Netherlands. ${ }^{6}$ Department of Pediatrics, Division of Neonatology, Erasmus MC, University Medical Center Rotterdam, Rotterdam, the Netherlands. ${ }^{7}$ Department of Public Health and Primary Care, Leiden University Medical Center/LUMC Campus, The Hague, The Netherlands.

\section{Corresponding author:}

Suzanne G.M.A. Pasmans, Department of Dermatology-Center of Pediatric Dermatology, Erasmus MC University Medical Center Rotterdam- Sophia Children's Hospital, Sp-1540, Wytemaweg 80, 3015 CN Rotterdam, The Netherlands.

\section{Conflict of Interest Statement:}

The Generation R Study is conducted by Erasmus MC University Medical Center Rotterdam in close collaboration with the School of Law and Faculty of Social Sciences of Erasmus University Rotterdam, the Municipal Health Service Rotterdam Metropolitan Area, the Rotterdam Homecare Foundation, and the Stichting Trombosedienst \& Artsenlaboratorium Rijnmond. The Dept Immunology of the Erasmus MC funded the immunological measurements. LD received funding from the European Union's Horizon 2020 research and innovation programme (LIFECYCLE, grant agreement No 733206, 2016; EUCAN-Connect grant agreement No 824989; ATHLETE, grant agreement No 874583). MCvZ is supported by the Australian National Health and Medical Research Council (NHMRC, Senior Research Fellowship 1117687). All authors declare that no competing interests exist. The Department of Dermatology of the Erasmus MC University Medical Center Rotterdam received an unrestricted grant from Micreos Human Health, the Netherlands.

\section{Funding statement}

LIFECYCLE, grant agreement No 733206, 2016; EUCAN-Connect grant agreement No 824989; ATHLETE, grant agreement No 874583; Australian National Health and Medical Research Council, Grant/Award Number: 1117687; European Union's Horizon 2020 research and innovation programme, Grant/Award Number: 733206; European Union's Horizon 2020 co-funded programme ERA-Net on Biomarkers for Nutrition and Health (ERA HDHL), Grant/Award Number: 696295. The Department of Dermatology of the Erasmus MC University Medical Center Rotterdam received an unrestricted grant from Micreos Human Health, The Netherlands.

\section{ABSTRACT}


Background: Mutations in the filaggrin gene $(F L G)$ affect epidermal barrier function and increase the risk of atopic dermatitis (AD). We hypothesized that $F L G$ mutations affect immune cell composition in a general pediatric population. Therefore, we investigated if school-aged children with and without FLGmutations have differences in immune cell numbers.

Methods: This study was embedded in a population-based prospective cohort study, the Generation $\mathrm{R}$ Study, and included 523 children of European genetic ancestry aged 10 years. The most commonFLG mutations in the European population (R501X, S1085CfsX36, R2447X and S3247X) were genotyped. Additionally, 11-color flow cytometry was performed on peripheral blood samples to determine helper $\mathrm{T}$ (Th), regulatory T (Treg) and $\mathrm{CD} 27^{+}$and $\mathrm{CD} 27^{-}$memory B cells. Sensitivity analysis was performed in $102 \mathrm{AD}$ cases, assessed by parental questionnaires.

Results: FLG mutations were observed in $8.4 \%$ of the total population and in $15.7 \%$ of the AD cases. Children with any $F L G$ mutation had higher Th22 cell numbers compared to $F L G$ wild-type children. Children with and without $F L G$ mutations had no difference in Th1, Th2, Th17, Treg or memory B cell numbers. Furthermore, in children with $\mathrm{AD}, F L G$ mutation carriership was not associated with differences in T- and B-cells or their subsets.

Conclusions: School-aged children with FLG mutations have higher Th22 cell, which might suggest an immunological defense mechanism to an altered skin barrier function. No associations between Th or Treg cells and FLG mutations suggests that FLGmutations do not otherwise affect immune composition in a general pediatric population.

\section{KEYS MESSAGE}

This study in a general pediatric population showed that filaggrin haploinsufficiency is associated with higher Th22, but not with other B- and T-cell subsets. FLG mutations did not affect immune cell composition in a subset of children with AD. Therefore, FLG mutations pose a risk to allergy development, but do not directly affect or confound immune measurements in children with atopic dermatitis.

\section{INTRODUCTION}

Filaggrin is a filament-associated protein that is encoded by the Filaggrin gene $(F L G),{ }^{1}$ and is an important contributor to the preservation of the skin barrier. ${ }^{1,2}$ Approximately $10 \%$ of the European population is heterozygote carrier of a disrupting mutation in $F L G .{ }^{3}$ Both complete loss-of-function and reduced functional activity of filaggrin lead to destruction of the stratum corneum (SC) and to skin barrier dysfunction. ${ }^{2,4}$ This barrier dysfunction due toFLG mutations is presumed to be caused by lower numbers of tight junctions, reduced density of the protein corneodesmosin and impaired maturation and excretion of lamellar bodies in the epidermis which are important in maintaining cell-to-cell integrity. ${ }^{1}$

Failure in barrier function through mutations in FLG results in increased skin permeability for percutaneous transfer of exogenous particles including allergens and pollutants including an increased permeability of the skin for percutaneous protein transfer. ${ }^{1,2,4}$ Accordingly, FLG mutations are the strongest genetic risk factor for atopic dermatitis (AD), predisposing to a form of AD that starts in early infancy and persists into adulthood. ${ }^{2,3,5}$ Previous meta-analysis showed that $F L G$ haploinsuffiency results in an odds ratio (OR) of 3.12 for $\mathrm{AD}^{6}{ }^{6}$ In addition, $F L G$ mutations in $\mathrm{AD}$ are associated with a higher incidence of skin infections or superinfections such as eczema herpeticum and a higher likelihood of having asthma, inhalant or food allergies. ${ }^{1,7-9}$

The increased permeability of the skin as a result of FLGmutations is thought to affect immune responses and maturation of adaptive immune cells. Filaggrin is also expressed in the thymus, the primary lymphoid organ in which $\mathrm{T}$ cells are formed. ${ }^{10}$ Hence, $F L G$ mutations potentially affect the peripheral immune cell compartment through effects in skin and thymus, and previous studies observed higher $\gamma \delta \mathrm{T} 17$, $\mathrm{T}$ helper (Th) 17 in mice bi-allelic for $F L G$ disruption. ${ }^{10} \mathrm{~A}$ case study reported higher numbers of circulating thymusemigrated regulatory $\mathrm{T}$ (Treg) cells, Th2 in with $6 \mathrm{AD}$ patients with a heterozygote $F L G$ mutation. ${ }^{11}$ Another study with 2 heterozygous, 2 homozygous and 1 compound heterozygous AD patient showed increased Th17 
cells in $F L G$-mutation group. ${ }^{12}$ On the other hand, literature on the role of B cell dysregulation in AD is scarce and conflicting. ${ }^{13-16}$. It can be hypothesized that mutations in $F L G$ can affect B-cell numbers due to skewing of the Th-cell population.

Because of the function of filaggrin in skin barrier tissue and in thymus, the presence of $F L G$ mutations might be a contributor to the shaping of $\mathrm{T}$-and $\mathrm{B}$ cell maturation in children. However, no studies on this association have been performed in the general pediatric population and only case studies have been performed in $\mathrm{AD}$ patients. ${ }^{11,12}$ Therefore, we here studied the associations between common $F L G$ mutations in the European population and immune cell numbers, as determined using with 11-color flow cytometry, within a population-based birth cohort study including a subgroup of AD patients.

\section{METHODS}

\section{Study design}

This study was embedded within the Generation R Study, a prospective birth cohort study located in Rotterdam, the Netherlands. The Medical Ethical Committee of the Erasmus MC, University Medical Center Rotterdam approved the study (MEC-2012-165). ${ }^{17}$ Written informed consent was obtained from parents or legal representatives of all children. We included all children with European genetic ancestry ${ }^{18}$ with information on filaggrin mutation (homozygous, compound heterozygous, heterozygous or wild type) and information on at least one of the immune cell outcomes. This resulted in a total number of 523 children (Figure 1).

Our subgroup of children with $\mathrm{AD}$, defined as physician-diagnosed eczema from parental questionnaires obtained at the child's age of 10 years ('Was your child ever diagnosed by a physician with atopic dermatitis', 'yes; no') consisted of 102 subjects. ${ }^{16}$

\section{$F L G$ genotype}

DNA samples obtained from umbilical cord blood were genotyped by modified Taqman allelic discrimination assays with the use of primers as described previously. ${ }^{19}$ The following 4 FLGmutations were identified: R501X (rs61816761), S1085CfsX36 (rs41370446), R2447X (rs138726443), and S3247X (rs150597413). $\cdot{ }^{19,20}$ Children were classified as having a $F L G$ mutation if they were homozygous, compound heterozygous or heterozygous for any of the four mutations. Children without any of the four mutations were classified as wild type.

\section{Immune cell numbers}

Peripheral blood samples from children were obtained at the age of 10 years. ${ }^{16}$ Absolute counts of CD ${ }^{+} \mathrm{T}$ cells and $\mathrm{CD}_{19}{ }^{+} \mathrm{B}$ cells per $\mu$ Lblood were determined with diagnostic lyse-no-wash protocol and detailed immunophenotyping was performed with 11-color flow cytometry (LSRII Fortessa, BD Biosciences). We determined naive $\left(\mathrm{CD} 45 \mathrm{RO}^{-} \mathrm{CCR} 7^{+}\right)$, effector memory RO-positive $\mathrm{T}$ cells (TemRO; $\mathrm{CD} 45 \mathrm{RO}^{+} \mathrm{CCR}^{-}$) and effector memory RA-positive $\mathrm{T}$ cells (TemRA; CD45RO-CCR7-) within $\mathrm{CD} 4^{+}$and $\mathrm{CD} 8^{+}$lineages. ${ }^{16,21,22}$ Within Treg cells, the differentiation in naive $\left(\mathrm{CD} 45 \mathrm{RA}^{+}\right)$and memory $\left(\mathrm{CD} 45 \mathrm{RA}{ }^{-}\right)$was determined. ${ }^{16}$ Finally, the following $\mathrm{T}$ helper $(\mathrm{Th})$ cell subsets $\left(\mathrm{CD} 4^{+} \mathrm{CD} 45 \mathrm{RA}^{-}\right)$were determined after exclusion of Treg cells: Th1 (CCR6 $\left.{ }^{-} \mathrm{CXCR}^{+}{ }^{+} \mathrm{CCR} 4^{-}\right)$, Th2 $\left(\mathrm{CCR}^{-}{ }^{-} \mathrm{CXCR} 3^{-} \mathrm{CCR} 4^{+}\right)$, Th17 $\left(\mathrm{CCR} 6^{+} \mathrm{CXCR}^{-} \mathrm{CCR} 4^{+} \mathrm{CCR} 10^{-}\right)$, Th17.1 $\left(\mathrm{CCR} 6^{+} \mathrm{CXCR} 3^{+} \mathrm{CCR} 4^{-}\right)$and $\mathrm{Th} 22\left(\mathrm{CCR} 6^{+} \mathrm{CXCR} 3^{-} \mathrm{CCR} 4^{+} \mathrm{CCR} 10^{+}\right) . \mathrm{s}$ In addition $\mathrm{CD} 27^{+}$and CD27- $\mathrm{IgG}^{+}, \mathrm{IgA}^{+}, \mathrm{IgE}^{+} \mathrm{CD} 19^{+} \mathrm{CD} 38^{\mathrm{dim}} \mathrm{IgD}^{-}$memory B cell subsets were defined. ${ }^{16}$ Gating strategies for immune cell determination were published previously. ${ }^{16}$

\section{Statistical Analyses}

First, characteristics of the study population were determined, stratified for $F L G$ mutations . P-values for determining differences between the categorical variables between the two groups were calculated with chisquared tests. Next, median cell numbers with interquartile range (IQR) were determined. Differences in cell numbers between children with and without FLG mutations were determined with the non-parametric MannWhitney U tests. Sensitivity analyses on the associations of $F L G$ genotype with immune cell numbers were 
performed within children who were diagnosed with AD. No adjustment for multiple testing was performed because of strong correlation between the immune cells studied. Statistical analyses were performed with SPSS version 21.0 (IBM Corp.) and R version 3.3.3 (R Foundation for Statistical Computing).

\section{RESULTS}

\section{Study population}

Characteristics of the study population are presented in Table 1. Within the total group of 523 children with European ancestry, filaggrin mutations were detected in $44(8.4 \%)$ children, including 3 biallelic mutations ( 2 compound heterozygous and 1 homozygous). The proportion of patients with AD was lower in the wildtype group compared to the group with $F L G$ mutations (20\% versus $42 \%$; p $<0.01$ ). Within the atopic dermatitis population, $15.7 \%$ children had a FLGmutation, including one biallelic mutation (homozygous). No differences were observed between other atopic diseases, including asthma, inhalant and food allergy and FLG mutation status (data not shown).

\section{Higher Th22 cell counts in children with FLG mutations}

Children with FLG mutation had higher Th22 cell numbers compared to children of the wild-type population (Figure 2A, eTable1). The median cell number within the $F L G$ mutation group was $5.60 / \mu \mathrm{L}$ (IQR 4.04;8.94) and within the wild-type group $4.54 / \mu \mathrm{L}$ (IQR $2.50 ; 7.38, \mathrm{p}=0.03$ ). In contrast, when studying this association in the atopic dermatitis population, no significant associations were observed (eFigure 1A).

\section{No associations between Th1, Th2, Th17 and Treg and FLGmutations}

No differences in median cell numbers between the FLG mutation and wild type group were observed for Th1, Th2, Th17 and Treg (Figure 2A, eTable 1). This was similar in the sensitivity analyses that only included children with atopic dermatitis (eFigure 1A). No differences in median cell numbers between the FLG mutation and the wild type group were observed for the effector memory CD4 ${ }^{+}$and $\mathrm{CD} 8{ }^{+} \mathrm{T}$ cell subsets: naive, Tcm, TemRA, TemRO (Figure 2B, eFigure 1B).

\section{No associations between memory $\mathrm{B}$ cells and FLG mutations}

No differences in median cell numbers between the $F L G$ mutation and the wild type group were observed for total B cells and naive mature B cells (eTable 1). In addition, no associations between FLGmutations and the following $\mathrm{CD}_{2} 7^{+}$and $\mathrm{CD} 27^{-}$memory B cell subsets were observed: $\operatorname{IgA}^{+}, \operatorname{IgE}^{+}, \operatorname{IgG}^{+}, \operatorname{IgM}^{+}\left(\right.$Figure $^{2}$ 3). Similarly, no changes were observed in the sensitivity analyses, which only included children with atopic dermatitis (eFigure 2, eTable 1).

\section{DISCUSSION}

In this population-based study among children of European genetic ancestry, we observed a prevalence of $8.4 \%$ for $F L G$ mutations. In addition, we demonstrated that children with $F L G$ mutations had higher Th22 cell numbers than children without FLG mutations. In contrast, the Th1, Th2, Th17, Treg and memory B cell numbers were comparable between children with and without $F L G$ mutations. In addition, among children with $\mathrm{AD}$, those with or without FLGmutations had no differences in B or T cell subsets.

\section{Comparison with literature and interpretation}

All previous studies on FLG mutations and immune cell numbers have been performed within mice models or smaller numbers of AD patients. ${ }^{10-12,23}$ This is the first study that provides insight in the role of $F L G$ mutations on immune cell numbers in school-aged children of a general population. The setting of this study within a population-based pediatric cohort study is unique to study the association of FLG on immune cell numbers in a general population.

In line with a previous study in mice, we observed higher Th22 cell numbers in children with $F L G$ mutations than in to children with wild type $F L G$ alleles. ${ }^{23} \mathrm{Th} 22$ cells are characterized by the production of IL-22 and contributes to skin integrity. ${ }^{24,25}$ Moreover, IL-22 is known for its role in the defense of different pathogens 
in the skin by the production of antimicrobial proteins. ${ }^{24,25}$ In $\mathrm{AD}$, acute skin lesions are associated with an upregulated Th22 immune response. ${ }^{26,27}$ We speculate that the observed higher number of Th22 cells is an immunological defense mechanism to the damaged skin barrier. Nevertheless, future studies should confirm this finding. When studying Th22 numbers only in AD children, no differences were observed between both groups. This is could be explained by the fact that children with AD have higher Th22 independent of their $F L G$ genotype. ${ }^{26}$ In addition, the expression of the protein filaggrin is decreased in $\mathrm{AD}$ which can cause Th22 alterations through skin barrier dysfunction independent of FLGmutation status. ${ }^{1,5}$ Unfortunately, literature on the effect of FLG mutations on the numbers of Th22 in AD is lacking.

In contrast with small previous case studies in AD, we did not observe differences in Th2, Th17 and Treg cell numbers between children with and without FLG mutations both in the total study population and in the subgroup of patients with AD. ${ }^{10-12,23}$ The associations of Th2, Th17 and Treg cell numbers with filaggrin in previous studies were explained by increased TSLP activity due to impaired skin barrier and impaired thymus functioning. ${ }^{11,28}$ In the thymus, an altered filaggrin expression affects maturation of $\mathrm{T}$ cells and induces dendritic cells to stimulate the differentiation of naive Treg cells into functionally different Treg cells. ${ }^{10,29}$ The discrepancies between previous studies and our current study could be explained by differences in investigated populations and species. The mice studies studied $F L G$ null mutations, in which no expression of filaggrin is present. ${ }^{10}$ This is in contrast with our population, encompassing mainly haploinsufficient children which leads to a $50 \%$ reduction in filaggrin expression. ${ }^{1}$ In addition, $F L G$ knockdown skin equivalents in previous studies could represent a different immunological setting than is present in human skin. ${ }^{23}$ Furthermore, it is likely that previous results on immune cell numbers in $\mathrm{AD}$ populations are affected by disease severity. Namely, immune cells in active AD skin can induce downregulation of filaggrin protein expression in the skin independent of FLG mutations, subsequently affecting immune cell composition. Although we do not have information on disease severity in our $\mathrm{AD}$ population, this study included a relatively healthy cohort in which we expect relatively mild $\mathrm{AD}$. A more severe $\mathrm{AD}$ phenotype has been linked to homozygous and compound heterozygous $F L G$ mutation phenotype. ${ }^{1}$ In addition, activated immune cells in more active AD skin can in itself downregulate filaggrin protein expression in the skin independent of FLG mutations and thereby affect skin barrier function and subsequently immune cell alteration. ${ }^{1,5} \mathrm{In}$ accordance, a previous study in AD patients observed that circulating Treg cell numbers were associated with AD activity and not withFLG genotype. ${ }^{11}$ In addition, we previously showed that children with AD had higher Th17 and Treg memory cell numbers. ${ }^{16}$ Therefore, alteration in immune cell numbers is probably not only dependent on FLG mutation genotype, but also on $\mathrm{AD}$ severity and epigenetic and environmental factors that affect these two, as our data suggest.

In addition, we did not observe differences in memory $\mathrm{B}$ cell numbers between children with and without $F L G$ mutations, nor any associations between memory $\mathrm{B}$ cell numbers and $\mathrm{AD}$ in our previous study. ${ }^{16}$ No previous studies have investigated B cell subsets in relation to $F L G$ mutations. Possibly, T cells are more affected by FLG mutations than B cells because of the effects of filaggrin in the thymus. ${ }^{10}$

\section{Methodological considerations}

A major strength is that this study investigated the association between $F L G$ genotype and a large panel of B and $\mathrm{T}$ cells in the general population for the first time. We had detailed and extensive information on immune cell numbers from 11-color flow cytometry and obtained objective information on genetic ancestry. However, the following limitations need to be addressed. First, the AD population for the sensitivity analyses was relatively small which could have limited the power in the statistical analyses. Nevertheless, in comparison to previous studies, only including a maximum of $6 \mathrm{AD}$ patients with $F L G$ mutations, this is the largest study on FLG mutations in both the general population and AD patients. Second, our AD population was defined by ever having physician diagnosed $\mathrm{AD}$ before or at the age of 10 years. Therefore, it is likely that a subset of the children has outgrown $\mathrm{AD}$ at the age of 10 and this might affect their immunophenotype. In addition, the use of questionnaires for $\mathrm{AD}$ diagnosis could have introduced recall bias. Third, as mentioned previously, our study included the four most common FLG mutations in the European population. To prevent misclassification, we selected children with genetic European ancestry for the current study. Although the 
choice for including the most common $F L G$ mutations in European populations is in line with previous studies ${ }^{11,12}$, other less frequent $F L G$ mutations could exist in low numbers since up to $113 F L G$ mutations resulting in premature protein termination have been described. A recent study including patients with AD and Ichthyosis Vulgaris (IV), showed that screening the entire encoding region of $F L G$ for mutations led to an improvement of the diagnostic yield. ${ }^{30}$ Furthermore, biallelic genotypes were only present in 3 children of the study population and therefore not studied separately. Since homozygous or compound heterozygous mutations lead to complete absence of filaggrin expression, these mutations might have different effects on immune cell numbers compared to heterozygous $F L G$ mutations which lead to $50 \%$ reduction in filaggrin expression. ${ }^{1}$ Therefore, studies investigating biallelic mutations compared to heterozygous $F L G$ mutations and wild type $F L G$ are needed. Furthermore, as this is the first study in a general cohort addressing the association between FLGmutation and immune cell numbers, future studies are needed for validation of our results.

In conclusion, within the general population, school-aged children with $F L G$ mutations have higher Th22 cell numbers. Furthermore, children with and without FLG haploinsufficiency did not differ in other B and T cell subsets. This suggests that with age, other factors such as environmental exposure contribute to risk that $F L G$ mutations poses to the development of allergy.

\section{ACKNOWLEDGMENTS}

We gratefully acknowledge the contribution of children and parents, general practitioners, hospitals and midwives, and pharmacies in pharmacies in Rotterdam. We thank the following parties for financially supporting our work: IFECYCLE, grant agreement No 733206, 2016; EUCAN-Connect grant agreement No 824989; ATHLETE, grant agreement No 874583; Australian National Health and Medical Research Council, Grant/Award Number: 1117687; European Union's Horizon 2020 research and innovation programme, Grant/Award Number: 733206; European Union's Horizon 2020 co-funded programme ERA-Net on Biomarkers for Nutrition and Health (ERA HDHL), Grant/Award Number: 696295. The Department of Dermatology of the Erasmus MC University Medical Center Rotterdam received an unrestricted grant from Micreos Human Health, The Netherlands. The funders had no role in the design or conduct of the study; the collection of the data and analyses; the interpretation of data; the preparation and review or approval of the manuscript; or the decision to submit the manuscript.

\section{ETHICAL APPROVAL STATEMENT}

The study was conducted according to the principles of the Declaration of Helsinki. The Medical Ethical Committee of the Erasmus MC, University Medical Center Rotterdam approved the study (MEC-2012-165). Written informed consent was obtained from parents or legal representatives of all children.

\section{REFERENCES}

1. Irvine AD, McLean WH, Leung DY. Filaggrin mutations associated with skin and allergic diseases. $N$ Engl J Med. 2011;365(14):1315-1327.

2. Sandilands A, Sutherland C, Irvine AD, McLean WH. Filaggrin in the frontline: role in skin barrier function and disease. J Cell Sci.2009;122(Pt 9):1285-1294.

3. Thyssen JP, Elias PM. It Remains Unknown Whether Filaggrin Gene Mutations Evolved to Increase Cutaneous Synthesis of Vitamin D. Genome Biol Evol. 2017;9(4):900-901.

4. Goleva E, Berdyshev E, Leung DY. Epithelial barrier repair and prevention of allergy. J Clin Invest. 2019;129(4):1463-1474.

5. McAleer MA, Irvine AD. The multifunctional role of filaggrin in allergic skin disease. $J$ Allergy Clin Immunol.2013;131(2):280-291.

6. Rodriguez E, Baurecht H, Herberich E, et al. Meta-analysis of filaggrin polymorphisms in eczema and asthma: robust risk factors in atopic disease. J Allergy Clin Immunol. 2009;123(6):1361-1370 e1367. 
7. Brown SJ, Asai Y, Cordell HJ, et al. Loss-of-function variants in the filaggrin gene are a significant risk factor for peanut allergy. J Allergy Clin Immunol. 2011;127(3):661-667.

8. Rice NE, Patel BD, Lang IA, et al. Filaggrin gene mutations are associated with asthma and eczema in later life. J Allergy Clin Immunol. 2008;122(4):834-836.

9. Chan A, Terry W, Zhang H, et al. Filaggrin mutations increase allergic airway disease in childhood and adolescence through interactions with eczema and aeroallergen sensitization. Clin Exp Allergy. 2018;48(2):147-155.

10. Jee MH, Johansen JD, Buus TB, et al. Increased Production of IL-17A-Producing gammadelta T Cells in the Thymus of Filaggrin-Deficient Mice. Front Immunol. 2018;9:988.

11. Moosbrugger-Martinz V, Gruber R, Ladstatter K, et al. Filaggrin null mutations are associated with altered circulating Tregs in atopic dermatitis. J Cell Mol Med. 2019;23(2):1288-1299.

12. Bonefeld CM, Petersen TH, Bandier J, et al. Epidermal filaggrin deficiency mediates increased systemic T-helper 17 immune response. Br J Dermatol. 2016;175(4):706-712.

13. Czarnowicki T, Esaki H, Gonzalez J, et al. Alterations in B-cell subsets in pediatric patients with early atopic dermatitis. J Allergy Clin Immunol. 2017;140(1):134-144 e139.

14. Czarnowicki T, Gonzalez J, Bonifacio KM, et al. Diverse activation and differentiation of multiple B-cell subsets in patients with atopic dermatitis but not in patients with psoriasis. J Allergy Clin Immunol. 2016;137(1):118-129 e115.

15. Heeringa JJ, Hajdarbegovic E, Thio HB, van Zelm MC. Systemic B-cell abnormalities in patients with atopic dermatitis? J Allergy Clin Immunol. 2016;138(1):317-318.

16. Looman KIM, van Meel ER, Grosserichter-Wagener C, et al. Associations of Th2, Th17, Treg cells, and IgA(+) memory B cells with atopic disease in children: The Generation R Study. Allergy.2020;75(1):178-187.

17. Kooijman MN, Kruithof CJ, van Duijn CM, et al. The Generation R Study: design and cohort update 2017. Eur J Epidemiol.2016;31(12):1243-1264.

18. Medina-Gomez C, Felix JF, Estrada K, et al. Challenges in conducting genome-wide association studies in highly admixed multi-ethnic populations: the Generation R Study. Eur J Epidemiol.2015;30(4):317-330.

19. Elbert NJ, Duijts L, den Dekker HT, et al. Role of environmental exposures and filaggrin mutations on associations of ethnic origin with risk of childhood eczema. The Generation R Study. Pediatr Allergy Immunol. 2016;27(6):627-635.

20. Kezic S, O'Regan GM, Yau N, et al. Levels of filaggrin degradation products are influenced by both filaggrin genotype and atopic dermatitis severity. Allergy. 2011;66(7):934-940.

21. Appay V, van Lier RA, Sallusto F, Roederer M. Phenotype and function of human T lymphocyte subsets: consensus and issues. Cytometry A.2008;73(11):975-983.

22. Sallusto F, Lenig D, Forster R, Lipp M, Lanzavecchia A. Two subsets of memory T lymphocytes with distinct homing potentials and effector functions. Nature. 1999;401(6754):708-712.

23. Wallmeyer L, Dietert K, Sochorova M, et al. TSLP is a direct trigger for T cell migration in filaggrindeficient skin equivalents. Sci Rep. 2017;7(1):774.

24. Eyerich K, Eyerich S. Th22 cells in allergic disease. Allergo J Int. 2015;24(1):1-7.

25. Fujita H. The role of IL-22 and Th22 cells in human skin diseases.J Dermatol Sci. 2013;72(1):3-8.

26. Czarnowicki T, He H, Krueger JG, Guttman-Yassky E. Atopic dermatitis endotypes and implications for targeted therapeutics. J Allergy Clin Immunol. 2019;143(1):1-11. 
27. Jiao Q, Qian Q, Liu C, et al. T helper 22 cells from Han Chinese patients with atopic dermatitis exhibit high expression of inducible T-cell costimulator. Br J Dermatol. 2020;182(3):648-657.

28. Chang J, Mitra N, Hoffstad O, Margolis DJ. Association of Filaggrin Loss of Function and Thymic Stromal Lymphopoietin Variation With Treatment Use in Pediatric Atopic Dermatitis. JAMA Dermatol.2017;153(3):275-281.

29. Tsilingiri K, Fornasa G, Rescigno M. Thymic Stromal Lymphopoietin: To Cut a Long Story Short. Cell Mol Gastroenterol Hepatol.2017;3(2):174-182.

30. van Leersum FS, Nagtzaam IF, van Oosterhoud CN, et al. Improving the diagnostic yield for filaggrin; concealed mutations in the Dutch population. J Allergy Clin Immunol. 2020;145(6):1704-1706 e1702.

TABLES

Table 1. Descriptives of the study population

\begin{tabular}{|c|c|c|c|c|c|c|}
\hline & & $\begin{array}{l}\text { Total } \\
\text { population }\end{array}$ & $\begin{array}{l}\text { Total } \\
\text { population }\end{array}$ & $\begin{array}{l}\text { Total } \\
\text { population }\end{array}$ & $\begin{array}{l}\text { Total } \\
\text { population }\end{array}$ & $\begin{array}{l}\text { Sensitivity } \\
\text { analyses }\end{array}$ \\
\hline $\begin{array}{l}\text { Child char- } \\
\text { acteristics }\end{array}$ & $\begin{array}{l}\text { Total } \\
(n=523)\end{array}$ & $\begin{array}{l}\text { Wildtype } \\
\text { population } \\
(\mathrm{n}=479)\end{array}$ & $\begin{array}{l}F L G \\
\text { mutation } \\
\text { population } \\
(\mathrm{n}=44)\end{array}$ & P-value & $\begin{array}{l}\text { Missing in } \\
\text { total study } \\
\text { population } \\
(\mathrm{N}, \%)\end{array}$ & $\begin{array}{l}\text { Atopic } \\
\text { dermatitis } \\
(n=102)\end{array}$ \\
\hline $\operatorname{Sex}(N, \%)$ & & & & 1.0 & 0.0 & \\
\hline Female & $280(53.5)$ & $256(53.4)$ & $24(54.5)$ & & & $48(47.1)$ \\
\hline Male & $243(46.5)$ & $223(46.6)$ & $20(45.5)$ & & & $54(52.9)$ \\
\hline $\begin{array}{l}F L G \\
\text { mutations (N, } \\
\%)\end{array}$ & & & & - & 0.0 & \\
\hline Wildtype & $479(91.6)$ & $479(100.0)$ & - & & & $86(84.3)$ \\
\hline $\begin{array}{l}1 \text { or more } \\
\text { mutations } \\
\text { Type } F L G \\
\text { mutations } \\
(\mathrm{N}, \%)\end{array}$ & $44(8.4)+$ & - & $44(100.0)$ & & & $16(15.7)$ \\
\hline $\begin{array}{l}\mathrm{S} 1085 \mathrm{CfsX} 36 \\
(\mathrm{rs} 41370446)\end{array}$ & $22(4.2)$ & - & $22(4.2)$ & - & 0.0 & $7(6.9)$ \\
\hline $\begin{array}{l}\text { R2447X } \\
\text { (rs138726443) }\end{array}$ & $6(1.1)$ & - & $6(1.1)$ & - & 0.2 & $1(1.0)$ \\
\hline $\begin{array}{l}\text { R501X } \\
\text { (rs61816761) }\end{array}$ & $18(3.5)^{2}$ & - & $18(3.5)^{2}$ & - & 0.4 & $9(9.0)++$ \\
\hline $\begin{array}{l}\text { S3247X } \\
\text { (rs150597413) }\end{array}$ & $0(0.0)$ & - & $0(0.0)$ & - & 0.4 & $0(0.0)$ \\
\hline $\begin{array}{l}\text { Ever } \\
\text { physician } \\
\text { diagnosed } \\
\text { atopic } \\
\text { dermatitis } \\
(\mathrm{N}, \%) \S\end{array}$ & $102(22.2)$ & $86(20.4)$ & $16(42.1)$ & 0.004 & 12.0 & $102(100.0)$ \\
\hline
\end{tabular}




\begin{tabular}{|c|c|c|c|c|c|c|}
\hline & & $\begin{array}{l}\text { Total } \\
\text { population }\end{array}$ & $\begin{array}{l}\text { Total } \\
\text { population }\end{array}$ & $\begin{array}{l}\text { Total } \\
\text { population }\end{array}$ & $\begin{array}{l}\text { Total } \\
\text { population }\end{array}$ & $\begin{array}{l}\text { Sensitivity } \\
\text { analyses }\end{array}$ \\
\hline Table 1 & Table 1 & Table 1 & Table 1 & Table 1 & Table 1 & Table 1 \\
\hline represents & represents & represents & represents & represents & represents & represents \\
\hline the child & the child & the child & the child & the child & the child & the child \\
\hline and & and & and & and & and & and & and \\
\hline maternal & maternal & maternal & maternal & maternal & maternal & maternal \\
\hline characteris- & characteris- & characteris- & characteris- & characteris- & characteris- & characteris- \\
\hline tics for the & tics for the & tics for the & tics for the & tics for the & tics for the & tics for the \\
\hline study & & study & study & study & study & study \\
\hline population & population & population & population & population & population & population \\
\hline stratified for & stratified for & stratified for & stratified for & stratified for & stratified for & stratified for \\
\hline$F L G$ & $F L G$ & $F L G$ & $F L G$ & $F L G$ & $F L G$ & $F L G$ \\
\hline mutations. & mutations. & mutations. & mutations. & mutations. & mutations. & mutations. \\
\hline Values are & Values are & Values are & Values are & Values are & Values are & Values are \\
\hline based on the & based on the & based on the & based on the & based on the & based on the & based on the \\
\hline non-imputed & non-imputed & non-imputed & non-imputed & non-imputed & non-imputed & non-imputed \\
\hline dataset and & dataset and & dataset and & dataset and & dataset and & dataset and & dataset and \\
\hline represented & represented & represented & represented & represented & represented & represented \\
\hline $\begin{array}{l}\text { as number } \\
(\%) \text {. }\end{array}$ & $\begin{array}{l}\text { as number } \\
(\%) \text {. }\end{array}$ & $\begin{array}{l}\text { as number } \\
(\%) \text {. }\end{array}$ & $\begin{array}{l}\text { as number } \\
(\%) \text {. }\end{array}$ & $\begin{array}{l}\text { as number } \\
(\%) \text {. }\end{array}$ & $\begin{array}{l}\text { as number } \\
(\%) \text {. }\end{array}$ & $\begin{array}{l}\text { as number } \\
(\%) \text {. }\end{array}$ \\
\hline Chi-squared & Chi-squared & Chi-squared & Chi-squared & Chi-squared & Chi-squared & Chi-squared \\
\hline tests were & tests were & tests were & tests were & tests were & tests were & tests were \\
\hline conducted & conducted & conducted & conducted & conducted & conducted & conducted \\
\hline to examine & to examine & to examine & to examine & to examine & to examine & to examine \\
\hline possible & possible & possible & possible & possible & possible & possible \\
\hline differences & differences & differences & differences & differences & differences & differences \\
\hline in baseline & in baseline & in baseline & in baseline & in baseline & in baseline & in baseline \\
\hline characteris- & characteris- & characteris- & characteris- & characteris- & characteris- & characteris- \\
\hline tics between & tics between & tics between & tics between & tics between & tics between & tics between \\
\hline the different & the different & the different & the different & the different & the different & the different \\
\hline genotypes. & genotypes. & genotypes. & genotypes. & genotypes. & genotypes. & genotypes. \\
\hline Abbrevia- & Abbrevia- & Abbrevia- & Abbrevia- & Abbrevia- & Abbrevia- & Abbrevia- \\
\hline tions: $F L G$, & tions: $F L G$, & tions: $F L G$, & tions: $F L G$, & tions: $F L G$, & tions: $F L G$, & tions: $F L G$, \\
\hline $\begin{array}{l}\text { maggrm } \\
\text { gene; N. }\end{array}$ & $\begin{array}{l}\text { maggrm } \\
\text { gene; N. }\end{array}$ & $\begin{array}{l}\text { maggrm } \\
\text { gene: N. }\end{array}$ & $\begin{array}{l}\text { nlaggrin } \\
\text { gene: } \mathrm{N} \text {. }\end{array}$ & $\begin{array}{l}\text { nlaggrin } \\
\text { gene: } \mathrm{N} \text {. }\end{array}$ & $\begin{array}{l}\text { nlaggrin } \\
\text { gene: N. }\end{array}$ & $\begin{array}{l}\text { nlaggrin } \\
\text { gene: N }\end{array}$ \\
\hline number; + & number; + & number; + & number; + & number; + & number; + & number; + \\
\hline Including 3 & Including 3 & Including 3 & Including 3 & Including 3 & Including 3 & Including 3 \\
\hline biallelic & biallelic & biallelic & biallelic & biallelic & biallelic & biallelic \\
\hline mutations (2 & mutations (2 & mutations (2 & mutations (2 & mutations (2 & mutations (2 & mutations (2 \\
\hline compound & compound & compound & compound & compound & compound & compound \\
\hline heterozy- & heterozy- & heterozy- & heterozy- & heterozy- & heterozy- & heterozy- \\
\hline gous and 1 & gous and 1 & gous and 1 & gous and 1 & gous and 1 & gous and 1 & gous and 1 \\
\hline homozy- & homozy- & homozy- & homozy- & homozy- & homozy- & homozy- \\
\hline gous) ++ & gous) ++ & gous) ++ & gous) ++ & gous) ++ & gous) ${ }^{++}$ & gous) ${ }^{++}$ \\
\hline Including & Including & Including & Including & Including & Including & Including \\
\hline one biallelic & one biallelic & one biallelic & one biallelic & one biallelic & one biallelic & one biallelic \\
\hline mutations & mutations & mutations & mutations & mutations & mutations & mutations \\
\hline (homozy- & (homozy- & (homozy- & (homozy- & (homozy- & (homozy- & (homozy- \\
\hline gous) $\S$ & gous) $\S$ & gous) $\S$ & gous) $\S$ & gous) $\S$ & gous) $\S$ & gous) $\S$ \\
\hline Based on & Based on & Based on & Based on & Based on & Based on & Based on \\
\hline parental- & parental- & parental- & parental- & parental- & parental- & parental- \\
\hline reported & reported & reported & reported & reported & reported & reported \\
\hline question- & question- & question- & 1question- & question- & question- & question- \\
\hline naires & naires & naires & naires & naires & naires & naires \\
\hline obtained at & obtained at & obtained at & obtained at & obtained at & obtained at & obtained at \\
\hline the child's & the child's & the child's & the child's & the child's & the child's & the child's \\
\hline age of 10 & age of 10 & age of 10 & age of 10 & age of 10 & age of 10 & age of 10 \\
\hline years: ever & years: ever & years: ever & years: ever & years: ever & years: ever & years: ever \\
\hline
\end{tabular}




\begin{tabular}{llllll}
\hline Total & Total & Total & Total & Sensitivity \\
population & population & population & population & \begin{tabular}{l} 
analyses \\
\hline
\end{tabular} \\
\hline
\end{tabular}

\section{FIGURE LEGENDS}

Figure 1. Flow chart of participants included in the study.

Abbreviations: Th, helper T cell; Treg, regulatory T cell.; Tcm, central memory T lymphocytes; TemRA, effector memory RA-positive T lymphocytes; TemRO, effector memory RO-positive T lymphocytes

Figure 2. Absolute numbers of blood T cell subsets stratified by Filaggrin Gene mutation status

Figure $2 A$ shows the median (IQR) cell count per $\mu$ Lblood for Th and Treg cell numbers stratified for $F L G$ mutation. Figure $2 B$ shows the median (IQR) cell count per $\mu$ Lblood for CD $4^{+}$and $\mathrm{CD} 8^{+}$effector memory $\mathrm{T}$ cell numbers stratified for FLG mutation. Abbreviations : IQR, interquartile range; Tcm, central memory T lymphocytes; TemRA, effector memory RA-positive T lymphocytes; TemRO, effector memory RO-positive T lymphocytes; Th, helper T cell; Treg, regulatory T cell. * denotes a two-sided P-value $<0.05$. Supplementary Table 1 and 3 show absolute numbers and p-values.

Figure 3. Absolute numbers of blood memory B cell subsets stratified by Filaggrin Gene mutation status Figure 3shows the median (IQR) cell count per $\mu \mathrm{L}$ blood for B memory cell numbers stratified for $F L G$ mutation. Abbreviations: IQR, interquartile range; Ig, Immunoglobulin. Supplementary Table 2 shows absolute numbers and p-values.

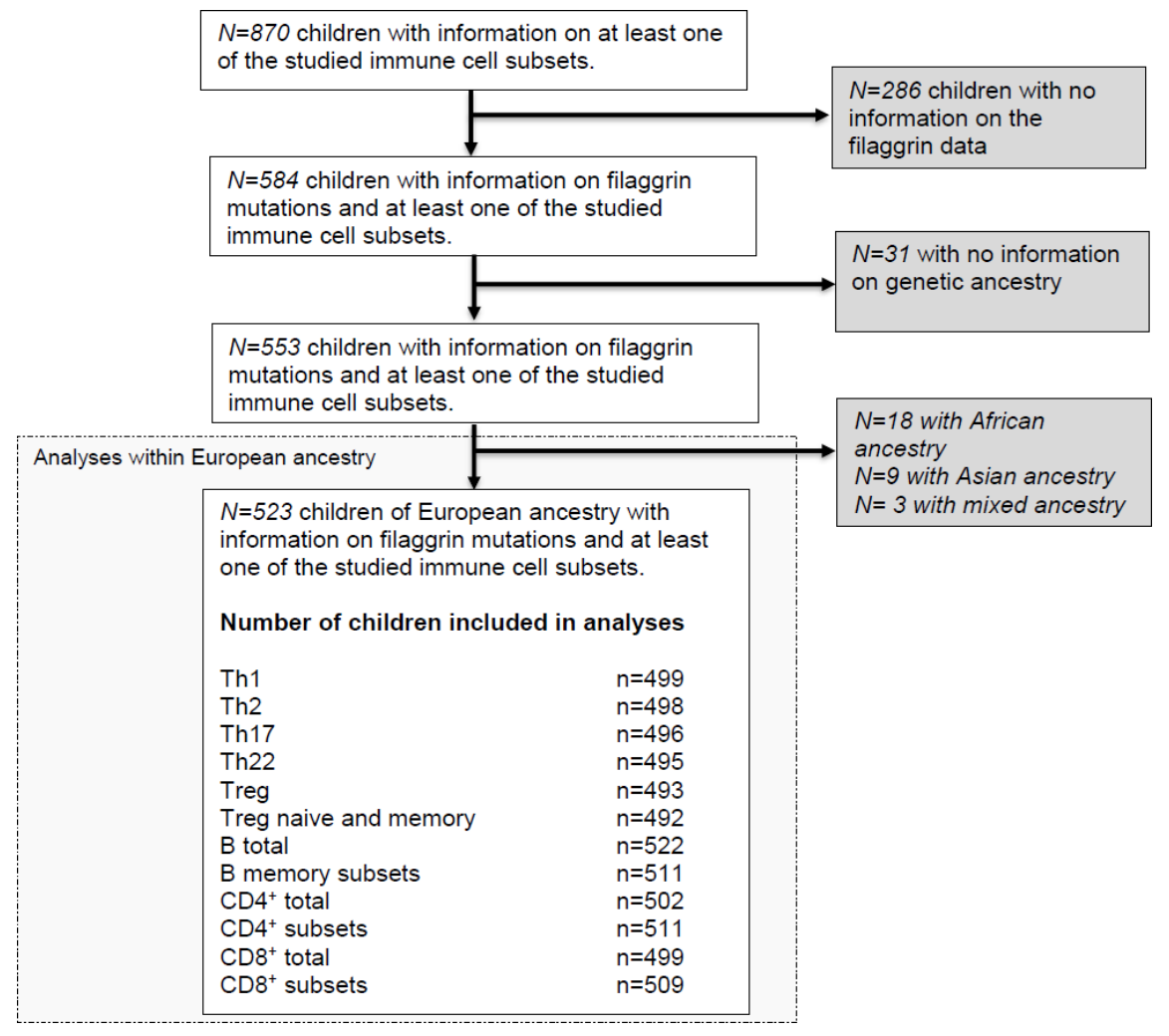



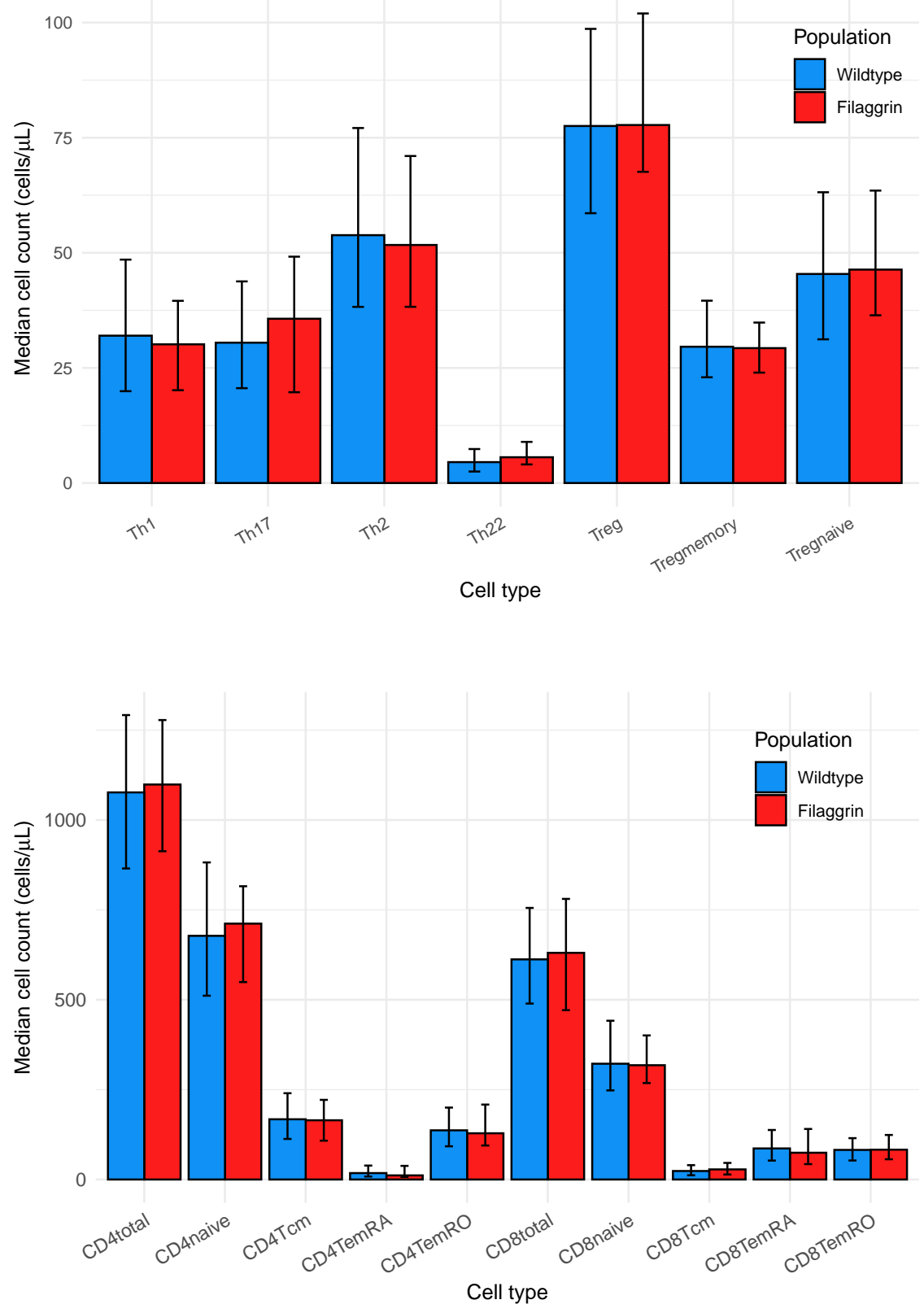


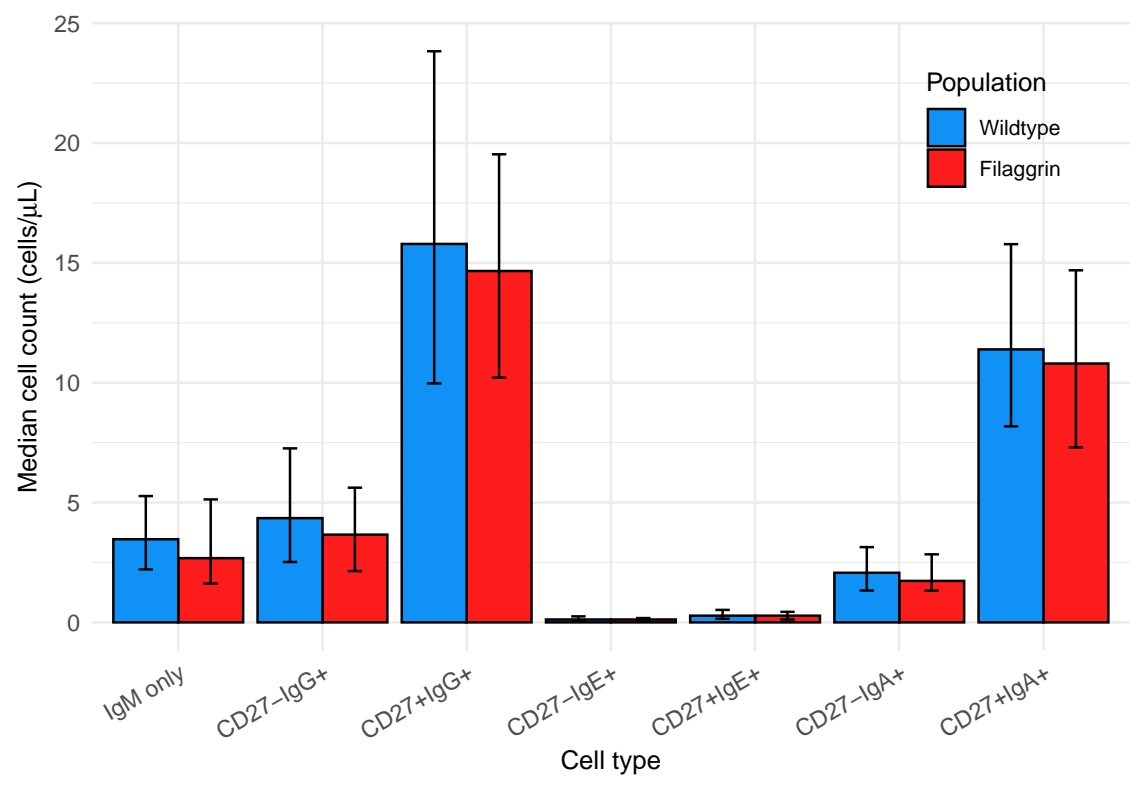

